\title{
FORMAÇÃO DOCENTE PARA A INFÂNCIA: Apontamentos à luz da Teoria Crítica
}

\author{
TEACHER EDUCATION FOR CHILDHOOD: notes in the light of critical theory
}

Natasha Yukari Schiavinato Nakata ${ }^{1}$

Flávia Regina Schimanski dos Santos. ${ }^{2}$

Tatiana de Freitas Silva ${ }^{3}$

Roberta Franciele Silva ${ }^{4}$

\section{http://dx.doi.org/10.52641/cadcaj.v6i4.518}

RESUMO: Considerando que atualmente o campo educacional se encontra tomado por uma fragilidade formativa, sobretudo, em relação à formação docente para a infância, este texto versa refletir sobre a formação de professores para a infância, com o intuito de encontrar resquícios de uma educação potencializadora e comprometida com a de barbárie social. As reflexões partiram das discussões relacionadas ao Programa de Pós-Graduação (Mestrado e Doutorado) em Educação pela Universidade Estadual de Londrina e da participação no GEPEITC - Grupo de Estudos e Pesquisa em Educação Infância e Teoria Crítica da mesma universidade. De caráter bibliográfico, nos apoiamos nos fundamentos da Teoria Crítica da Sociedade cujos principais nomes são Theodor Adorno e Max Horkheimer e em autores contemporâneos que dialogam com essa mesma corrente filosófica. O estudo revela que, formar professores críticos resultaria, portanto, em uma educação para a infância humanizadora, em suas relações de afeto, sensibilidade ou outro, com um pensamento coletivo que vislumbre uma mudança social frente à sociedade administrada, instrumentalizada e de contradições.

Palavras-chaves: Formação Docente. Infância. Teoria Crítica.

\begin{abstract}
Considering that currently the educational field is taken by a formative weakness, especially in relation to teacher training for childhood, this text is about reflecting on the training of teachers for childhood, in order to find remnants of an empowering and committed education with that of social barbarism. The reflections started from the discussions related to the Graduate Program (Master and Doctorate) in Education by the State University of Londrina and participation in GEPEITC - Group of Studies and Research in Childhood Education and Critical Theory at the same university. Bibliographic in nature, we rely on the foundations of Critical

\footnotetext{
${ }^{1}$ Universidade Estadual de Londrina (UEL), Londrina-PR-Brasil. Doutoranda do programa de pós-graduação em Educação. ORCID: http://orcid.org/0000-0002-7455-8504. E-mail: naaschiavinato@gmail.com

${ }^{2}$ Universidade Estadual de Londrina (UEL), Londrina-PR-Brasil. Doutoranda do programa de pós-graduação em Educação. ORCID: https://orcid.org/0000-0002-4583-0193. E-mail: flaviaschimanski@gmail.com

${ }^{3}$ Universidade Estadual de Londrina (UEL), Londrina-PR-Brasil. Mestranda do programa de pós-graduação em Educação. ORCID: https://orcid.org/0000-0002-3668-1616.E-mail: taty freitas09@hotmail.com

${ }^{4}$ Universidade Estadual de Londrina (UEL), Londrina-PR-Brasil. Mestranda do programa de pós-graduação em Educação. ORCID: https://orcid.org/0000-0002-5633-5323 .E-mail: betauel2014@gmail.com
} 
Theory of Society whose main names are Theodor Adorno and Max Horkheimer and contemporary authors who dialogue with this same philosophical current.

Key-words: Teacher Education. Childhood. Critical Theory.

\section{INTRODUÇÃO}

Neste texto buscaremos refletir sobre a formação de professores para a infância, com o intuito de encontrar resquícios de uma educação potencializadora e comprometida com a desbarbárie social. Para tal objetivo, cumpre responder a emblemática indagação sobre como a Teoria Crítica da Sociedade tem contribuído para a formação de professores no que diz respeito ao processo de formação humana na infância? A temática é urgente para ser repensada no campo da educação, visto que o cenário que se encontra é de fragilidade formativa e desvalorização das questões educacionais, sobretudo, em relação à formação docente para a infância.

Culturalmente, a educação para infância está inserida em um patamar de desprestígio em relação aos outros níveis e modalidades de ensino, devido ao grande equívoco sobre o que é, para quê e quais são seus objetivos e, ainda, a concepção que se tem sobre a relação criança-infânciaeducação. Ainda que a trajetória de mais de vinte anos do estabelecimento da LDBEN/1996, tenha apresentado mudanças significativas para o campo da formação de professores da Educação Infantil e, de modo geral, no reconhecimento dessas instituições enquanto parte da educação básica, esses avanços não foram suficientes para proporcionar um atendimento de qualidade nos espaços da Educação Infantil, nem tampouco para promover a valorização dos profissionais que atuam na educação da infância e propiciar práticas educativas que sejam adequadas para o desenvolvimento das crianças.

É preciso que haja formação de professores e de crianças na infância humanizadoras e que culmine na reflexão e resistência na sociedade de contradições. Primeiramente, o artigo aponta o conceito de semiformação de professores na infância e suas implicações sociais e formadoras. Em seguida, apresenta como essa mesma semiformação pode ser vista como despontencializadora da formação humana e lúdica das crianças, relacionando essas implicações com a Indústria Cultural. Adiante é estabelecido um diálogo com Arendt (2016), que contribui ricamente para pensarmos uma educação mais igualitária e humana e, em seguida, apresentamos um tópico acerca da educação e formação contra a barbárie vindo a clarificar o conceito de educação preconizada pela Teoria Crítica da Sociedade. Ao final, tecemos alguns comentários a título de conclusão e a suscitação de novos questionamentos. 


\section{A (SEMI) FORMAÇÃO DE PROFESSORES DA INFÂNCIA}

A Teoria Crítica da Sociedade, por meio do método dialético, nos impulsiona a pensar de forma crítica e humanizada alguns pontos importantes desta base teórica que contribuem efetivamente para a formação de professores da infância. Tal teoria percebe a realidade como ela é e como ela deveria ser, buscando identificar os obstáculos que impedem essa lacuna. Na Teoria Crítica não há superação - conciliação - mas a reflexão e esclarecimento. Não há necessidade de trazer soluções, mas sim de apresentar as contradições. Por isso, para ser crítica, a teoria deve visar a emancipação. Precisa ser a teoria da imanência, ou seja, partir da realidade e a ela se voltar e, também, da transcendência, retornar ao campo das ideias.

$\mathrm{Na}$ trajetória de mais de vinte anos de promulgação da LDBEN/1996, ocorreram mudanças significativas no que se refere a formação de professores da Educação Infantil e, de modo geral, no reconhecimento dessas instituições enquanto parte da educação básica. Todavia, esses avanços não foram suficientes para proporcionar um atendimento de qualidade dentro destas instituições, promover a valorização dos profissionais que atuam na educação da infância e propiciar práticas educativas que sejam adequadas para o desenvolvimento das crianças.

Neste viés, pela ótica da Teoria Crítica da Sociedade, nota-se que em pleno século XXI a educação ainda tem se direcionado a uma ação formativa mecânica, manipulada e administrada pelo sistema capitalista tardio que, de forma explícita e implícita, se aproveita deste processo alienante e veicula diariamente fatos culturais desprovidos de seu potencial crítico, estimulando a permanência dos indivíduos a sua menoridade na experiência do pensar e reforçando-a pelas muralhas sólidas da semiformação, corroborando para estruturar o "sempre-igual" travestido de novo.

Dentre os filósofos da Escola de Frankfurt, Adorno (2003) nos leva a refletir sobre esses aspectos, uma vez que afirma que a formação cultural foi obstruída em sua dimensão crítica na medida que reduziu-se à semiformação. Por isso, pelas lentes da Teoria Crítica da Sociedade, a formação encontra-se danificada pelo sistema capitalista, uma vez que não garante aos profissionais que atuam na área da educação uma formação autorreflexiva dotada de ações emancipatórias do ensino no sentido de desenvolver o trajeto de estranhamento e reapropriação entre o espírito e o mundo.

De acordo com Silva (2014, p. 89, grifos nossos),

[...] o predomínio do tecnicismo como vertente pedagógica repercutiu no perfil do professor que atuava junto às classes populares: a este professor bastava $\mathrm{O}$ domínio de habilidades técnicas destinadas a subsidiar a reprodução do conhecimento disciplinar prescrito nos livros didáticos. Se o papel da escola era 
reduzido a adaptar esses trabalhadores ao mercado de trabalho, os seus professores não precisavam de formação aprofundada. Daí a desvalorização deste profissional do ponto de vista da sua formação e de seu entendimento, afinal, qualquer um servia para ser professor naquela situação.

No século atual, a desvalorização deste profissional se manifesta por meio das inúmeras medidas implementadas pelas políticas públicas e empresariais - como contenção salarial, aumento de crianças dentro das salas de aula, supervalorização dos livros didáticos, dentre outros - e, também, pela falta de reconhecimento de sua autoridade e da importância de sua profissão, a qual tem sido considerada dispensável para a sociedade globalizada. Essa situação se intensifica quando voltamos nossos olhares para os professores da infância, os quais são rebaixados a um lugar secundário no processo de ensino-aprendizagem com a justificativa de uma autoridade desacreditada e desvalorizada dentro das salas de aulas.

As licenciaturas estão cada vez mais condicionadas a formar profissionais que atendam às vontades e exigências do mercado, ou seja, tomam o aluno como cliente, como centro do processo e a carreira como uma pista de corridas em que o produtivismo determina a qualidade profissional. Desta maneira, o professor passa a ser mensurado em função do número de títulos que tem e em função do número de publicações que possui, esquecendo-se da sua capacidade formativaintelectual.

A esta lógica, exige-se cada vez mais que os professores sejam capazes de solucionar novos problemas com maior eficiência e rapidez, acompanhando as mudanças e educando-se frequentemente. Dentro deste contexto, surgem os cursos aligeirados de formação profissional, as certificações apenas formais, a formação superior aligeirada, resultando em uma certificação vazia. O problema é que tais profissionais se iludem acreditando que estão enriquecendo seu cabedal cultural, quando na verdade estão apenas fazendo uso de uma formação destituída de emancipação.

Podemos perceber com facilidade que a lógica predominante da sociedade capitalista atual é estritamente quantitativa, pois "valoriza a quantidade de informações em detrimento da possibilidade de síntese dos conteúdos e de sua inserção na realidade dos educandos" (BANDEIRA; OLIVEIRA, 2012, p. 230). Exige-se cada vez mais a memorização de fórmulas e técnicas, que serão rapidamente esquecidas, sem preocupar-se com a relação destas informações com os fatos históricos e sociais. A escola contemporânea transformou-se em um espaço de propagação da semiformação e da barbárie, pelo processo de reprodução servil do conhecimento. Exige-se cada vez mais que os professores tenham conhecimento de várias áreas (ciências, matemática, geografia, língua portuguesa), no entanto, esses conhecimentos se tornam vagos, pois não há um aprofundamento teórico.

Sobre esse aspecto, Oliveira e Bueno (2016, p. 242) afirmam que, 
A expropriação da possibilidade de pensamento crítico é acompanhada pela semiformação que privilegia o saber técnico em detrimento do saber filosófico, obstruindo a reflexão sobre a educação. A atividade docente transformou-se em mera técnica [...], atendendo à necessidade social de aumento da eficiência à demanda de qualificação profissional. A formação vai dissolvendose como experiência formativa coisificada e esvaziada de conteúdos [...], impedindo que se forneçam ao professor formas para refletir sobre os problemas que ele enfrenta.

O problema de um professor semiformado é que ele resiste à real formação, pois não tem consciência de suas debilidades. Ser semiformado não significa possuir uma formação pela metade, mas sim ter uma formação deficiente que, porém, se consolida (BANDEIRA; OLIVEIRA, 2012). Essa falta de consciência sobre a própria debilidade formativa vem da falta de conhecimento e, também, de um processo incompleto de aprendizagem, uma vez que esta supõe um momento de assimilação e adaptação, e posteriormente de própria produção. No caso destes profissionais, esse processo parou na primeira fase e ainda de forma superficial, tornando-os reféns das informações que são mediadas pelo sistema capitalista e pela Indústria Cultural.

Adorno (2003) afirma que existem possibilidades de resistência a essa semiformação no interior dos processos educativos, mas, para que isso ocorra, é preciso desenvolver propostas educativas voltadas à criticidade e à reflexão. Por isso, segundo o filósofo, para que Auschwitz não se repita, é necessário educar desde cedo as crianças. Afinal, "o processo de conscientização se desenvolve paralelamente ao processo de promoção da espontaneidade" (ADORNO, 2003, p. 147). Em síntese, quanto mais esclarecidas forem as crianças, mais chances elas terão de ser indivíduos conscientes e de viver em um mundo humanizado e emancipado.

\section{A (DES) POTENCIALIZAÇÃO FORMATIVA E LÚDICA NA INFÂNCIA}

A vida humana está permeada pela ludicidade. As experiências lúdicas vivenciadas pelo homem quando criança no seio familiar, suas conversas, risadas e amizades, a música, o ouvir e ler histórias, o canto e a dança, o brincar de faz de conta, os brinquedos, jogos e brincadeiras com o outro ou sozinho caracterizam o lúdico. Essas vivências são decisivas para o desenvolvimento psíquico, motor e afetivo, e contribuem na formação dos sujeitos ao longo de sua vida adulta. Para Huizinga (2000), a ludicidade é caracterizada como atividade humana que possibilita a formação dos homens enquanto tal, assim como também a sua subjetividade.

Para discutirmos os processos de (des) potencialização formativa e lúdica na infância no contexto da sociedade capitalista, se faz importante entendermos que essa formação é perpassada pela Indústria Cultural, termo este elaborado por Adorno e Horkheimer no ano de 1947 e que permeia grande parte das discussões elaboradas pelos intelectuais da Escola de Frankfurt. 
A Indústria Cultural surge a partir da análise crítica dos filósofos de Frankfurt acerca da realidade instaurada na II Guerra Mundial (1945), sob o modelo de governo nazifascistas comandados por Adolf Hitler. Para esses intelectuais, a Indústria Cultural é definida como um conjunto de meios de comunicação como a televisão, rádio, jornais e revistas que quando acessível às massas resultam em lucros grandiosos na indústria do entretenimento. Sobre o desenvolvimento da indústria da comunicação de massa, Adorno e Horkheimer (1947, p. 1), declaram:

O cinema e o rádio não precisam mais se apresentar como arte. A verdade de que não passam de um negócio, eles a utilizam como uma ideologia destinada a legitimar o lixo que propositalmente possuem. Eles se definem a si mesmos como indústrias, e as cifras publicadas dos rendimentos de seus directores gerais suprimem toda dúvida quanto à necessidade social de seus produtores.

Assim, a Indústria Cultural se caracteriza por uma máquina de fazer cultura que massifica os produtos culturais e de valores, transformando tudo em mercadoria, até mesmo as relações humanas.

As ruínas deixadas no pós guerra (1989-1945), acarretaram profundas mudanças no âmbito social, cultural e político na vida humana, resultando na reorganização do sistema capitalista a partir de um modelo neoliberal que passou a tornar toda forma de arte e estética como meio de preservação e expansão do capital, estabelecendo um processo de manipulação e de dominação que passou a atingir toda a sociedade, sobretudo as relações entre educação e infância, visto que o meio social o qual as crianças estão inseridas se faz responsável por sua formação cultural, interferindo de forma significativa em sua maneira de agir e pensar. Nesta perspectiva, Adorno (1995, p. 121) afirma que "a educação tem sentido unicamente como educação dirigida a uma autoreflexão crítica".

Em busca de compreender como a Indústria Cultural foi e é responsável pelo conformismo e adaptação do indivíduo desde a infância, os autores da Escola de Frankfurt vão para além da análise realizada por Marx acerca das relações de produção através dos autores Descartes (2003), Kant (1783), Marx (1999) e Freud (1978), e outras áreas do conhecimento, de forma a desvelar as contradições existentes na sociedade ao olhar também para a subjetividade a fim de transformá-la.

Para a Teoria Crítica, por meio da razão, o homem foi capaz de desenvolver-se em suas formas humanas e tecnológicas, o que possibilitou criar e recriar sua realidade, contudo, a mesma razão transformou os homens escravos de si mesmos, em meio a banalização de sua própria criação. Dessa maneira, Oliveira e Agostini (2020, p. 4) pontuam que "a racionalidade técnica hoje é a racionalidade da própria dominação". 
Corroborando com essa afirmação, Oliveira (2018, p. 31) afirma que a Indústria Cultural “dissemina padrões comportamentais de ajustamento dos indivíduos ao processo mais amplo de circulação do capital, constituindo assim, a padronização de comportamentos, desejos, idéias, conforme à mercadoria" revelando, portanto, o poder e controle social como também é legitimada pela própria demanda social, mas que é resultado do próprio poder de persuasão da indústria.

Silva e Bueno (2017, p. 1175), reverberam que a Indústria Cultural tem se tornado um veículo de semiformação na infância, adaptando-as e transformando-as em conformidade com a sociedade moderna. Para os autores, a "formação deve ser compreendida como cultura pela apropriação subjetiva; de outra forma, converte-se no contrário", ou seja, em uma formação humana que se baseia em uma cultura conformista e do consumo. Em síntese, a ideologia da Indústria Cultural tem como instrumentos de despotencialização, a manipulação, o controle e a administração, conseguindo incutir nas crianças e adultos a falsa percepção de que suas necessidades, desejos e vontades são próprios de si.

As contradições entre sociedade e infância também estão presentes na docência. Embora por um lado temos o prestígio da docência universitária e por outro a desvalorização do professor da Educação Infantil, esses profissionais são cobrados quanto a sua formação para exercício da profissão, contudo, essa mesma sociedade baseada no capital é incapaz de oferecer condições adequadas de formação e trabalho, fornecendo apenas uma formação aligeirada e fragmentada associando a educação a técnica e a economia, eliminando toda experiência necessária ao processo de formação humana como preconizou Benjamin (1987).

Destarte, a compreensão dos processos de (des) potencialização formativa na infância requerem um olhar para conjuntura social e os fatores que marcam os processos de constituição e formação dos sujeitos na sociedade vigente, administrada pela racionalidade técnica, intimamente ligada à semiformação de professores em decorrência de uma formação imediatista como projeto social e econômico que presa por uma formação prática, técnica e utilitária.

Nesse sentido, a crítica feita pela escola de Frankfurt a formação dos sujeitos culmina no fato de que a educação deve ter como premissa a ampliação dos conhecimentos desde a mais tenra idade, de maneira que adquiram uma consciência que desperte para a ação mesmo que a sociedade exija homens adaptados e conformados. Para Adorno (2011, p. 143-144), "a educação seria impotente e ideológica se ignorasse o objetivo de adaptação e não preparasse os homens para se orientarem no mundo. Porém, ela seria igualmente questionável se ficasse nisto".

Neste contexto, a Teoria Crítica da Sociedade se justifica pelo seu próprio compromisso em desvelar a ordem social posta. Por isso, o lugar da infância na Teoria Crítica está em oportunizar 
às crianças ainda pequeninas uma formação contrária à frieza instaurada na sociedade moderna através de uma educação com valores humanistas frente a sociedade de contradições.

Compreende-se, portanto, que ações de manipulação, dominação e administração resultam em um processo de instrumentalização da razão e, por conseguinte, alienação, impossibilitando a (des) potencialização formativa e lúdica das crianças tendo como resultado a semiformação. Neste contexto, a escola e os professores assumem o grande desafio de possibilitar às crianças uma educação que potencialize a construção crítica e reflexiva e que culmine na emancipação.

\section{EDUCAÇÃO E FORMAÇÃO: DIÁLOGOS COM HANNAH ARENDT}

A perspectiva crítica dos filósofos da Escola de Frankfurt que elaboraram a Teoria Crítica da Sociedade, manteve aproximações com importantes pensadores do século XX, principalmente, no que se refere a uma "submissão" intelectual em que os sujeitos são condicionados pela estrutura social e pelo modelo econômico capitalista. As críticas que se concentram nessa temática convergem no sentido de possibilitar a tomada de consciência dos sujeitos, a fim de que possam questionar, analisar e romper com a postura conformada a que são condicionados.

Como uma influente pensadora do século XX, Hannah Arendt discutiu temas urgentes da época - como a ascensão dos regimes totalitários na Europa - analisando fatos e tecendo críticas em defesa da humanidade que estava sendo destruída pelos governos extremistas. Ainda, debruçouse em reelaborar as categorias políticas que estavam sendo rompidas pelo caos da modernidade. Muitos de seus ideais têm confluência com a Teoria Crítica, sobretudo, a análise crítica dos fenômenos sombrios e destrutivos para a vida humana causados pelo Nazismo, sobretudo, o impedimento do direito à vida.

A obra arendtiana se estabelece em um contexto de fragilidade política, em que conceitos da tradição foram rompidos e passaram a ter sentido e significado impostos pelo prisma do horror totalitário, isto é, passaram por um esvaziamento de seus reais sentidos. Categorias como poder, autoridade, liberdade e até mesmo a própria política foram distorcidas. Ao se preocupar com a reconstrução das categorias políticas solapadas pela modernidade, a autora defendeu intelectualmente o "direito a ter direitos" (LAFER, 2018). A ênfase na expressão "direitos a ter direitos" representa a análise da autora sobre a destituição do espaço público por alguns homens, como no caso dos judeus que foram expulsos da participação política, perdendo a legitimidade de fala e de escuta. Tal período foi marcado nos estudos arendtianos como a ausência de dignidade da política. 
Para Arendt (2016) sem um espaço político que possibilite condições para o fenômeno político da igualdade, como a livre linguagem e expressão de todos, inexiste a asserção aos direitos e, assim, se estabelece um palco de injustiça, coerção, violência, instaura-se um modelo de governo pautado na barbárie, como expressa Adorno (2003).

É sobre essas reflexões que ambos os autores passam a repensar o campo da educação e do próprio processo formativo de docentes e estudantes, com atenção especial ao papel do ensino e da autoridade pedagógica responsável na formação da criança desde a primeira infância. A criança como objeto da educação, está iniciando seus primeiros passos em um mundo novo e, se concentra em um estado que a Arendt (2016) denomina de "vir a ser", em outras palavras, a criança é um ser humano em processo de formação. Logo, compreender que esse processo de formação dos mais novos, precisa necessariamente de um direcionamento com autoridade, necessita da interligação entre o pensamento e a ação. Agir nesse caso, é tomar consciência da responsabilidade e traçar um trajeto contrário da barbárie que está se repetindo, além de assumir o compromisso de se responsabilizar pela formação adequada dos mais jovens.

Para Adorno (2003) a ausência de reflexão e a tendência a visão estereotipada de mundo demonstra uma consciência totalitária. Em seus estudos, Adorno e Arendt nos direcionam para a superação da crise da educação, que contribui para a desbarbarização e resistência ao fascismo e ao totalitarismo e os efeitos que causaram na dinâmica do mundo e nas relações sociais e humanas. A luta contra a barbárie no mundo e a superação dos aspectos semiformativos que pairam sobre a educação e sobre a formação dos professores perpassam pela tomada de consciência e pela capacidade de autorreflexão de cada indivíduo.

Por conseguinte, uma das principais contribuições da Teoria Crítica da Sociedade para o âmbito educacional, refere-se a defesa de um pensamento crítico capaz de romper com as barreiras da subjetividade, permitindo aos sujeitos a identificação da barbárie e a possibilidade de transformála, visto que, nessa perspectiva somente uma sociedade mais justa e igualitária poderá ser capaz de ter condições para a democratização do pensamento crítico. O autor aponta para a importância da emancipação do sujeito, como possibilidade de desenvolver uma capacidade individual de sair da vulnerabilidade e resistir à opressão, exploração e demais formas de violência estabelecidas na sociedade.

No mesmo sentido, Arendt (2016) defende a atividade autônoma do pensamento. São denominações diferentes, mas caminham em um mesmo sentido e direcionam-se com vistas a capacidade de autorreflexão dos sujeitos para a construção de uma personalidade autônoma, com uma consciente capacidade de resistência ao fascismo e ao totalitarismo, bem como os ditames do capital que lesam a vida humana e o próprio direito de existência em um espaço comum. 
Outras considerações que merecem a nossa atenção em relação aos possíveis rumos para a educação e para a formação docente, trata-se da proposta de desbarbarização de Adorno (2003) autor aponta caminhos que não se devem seguir nos processos educativos. O primeiro é sobre a “educação como dureza”, justamente a ação autoritária. Esse tipo de relação desigual entre professor e estudante, produz efeitos negativos para o desenvolvimento dos mais novos. Como bem explicam Zuin; Pucci; Oliveira (2001, p.132) “Aquele que é duro consigo mesmo julga adquirir o direito de sê-lo também com os outros".

Em termos de relações humanas, os sujeitos educados neste modelo de educação se tornam adultos competitivos e autoritários, sem empatia e sem a capacidade de exercer um pensamento sobre a realidade. Outro aspecto representa a prática do esporte e a maneira como o professor lida com a competição no processo de ensino. As modalidades esportivas podem ser um relevante instrumento educativo e uma manifestação cultural de encontro social, de competição pautada no respeito entre adversários, no entanto, pode ser também um gerador de tensões e agressões "seja entre seus participantes, como entre seus torcedores (ZUIN; PUCCI; OLIVEIRA, 2001).

Contudo, o professor precisa de condições formativas para desenvolver um trabalho consciente e significativo para a formação de seus estudantes. Os autores não nos fornecem um receituário de uma ação transformadora exata a ser desenvolvida pelo professorado, porém, nos indicam possibilidades de enfrentamento daquilo que há tempos vem se repetindo e, sobretudo, elementos para pensar, repensar e ressignificar continuamente a consciência de agir politicamente com vistas ao bem comum e para uma educação potencializadora da capacidade de formular juízos.

\section{EDUCAÇÃO E FORMAÇÃo CONTRA A BARBÁRIE}

A semiformação docente no contexto de uma sociedade danificada e pautada pelo modelo neoliberal tem sido gatilho para propagação da barbárie nos espaços escolares. Para Adorno (2003), o processo de desbarbarizar é a questão mais urgente da educação, por isso, pensar na formação docente se faz tão urgente quanto. Silva (2019, p. 93) corrobora afirmando que:

A educação, por encontrar-se inserida em uma configuração social danificada, não tem permitido a autonomia dos indivíduos. Ela tem cumprido, no capitalismo, uma tarefa basilar para a dominação dos indivíduos: desviar a atenção do manifesto segredo ideológico. Segredo esse o qual as massas nem desconfiam, mas que é vital para que a dominação permaneça inalterada.

Deste modo, é preciso pensar numa educação que conduza à emancipação, impulsionando para autorreflexão, despertando o indivíduo da racionalidade instrumental, da semiformação e da indústria de massas. Adorno (2003), defende que a formação dos sujeitos contra a reprodução da 
barbárie está condicionada a uma educação que promova a reflexão. Por barbárie, Adorno (2003. p. 154), entende que "[...] a civilização em seu mais alto nível tecnológico, as pessoas se encontram atrasadas/disforme em relação a sua própria civilização, mas também tomadas por uma agressividade primitiva, ódio primitivo, impulso para destruição”. Diante disso, “[...], o único poder efetivo contra a repetição de Auschwitź é a conquista de uma educação autorreflexiva".

Como dito anteriormente, o processo semiformativo tem sido conduzido pela razão técnica e instrumental, ou seja, enfatizando as exigências mercadológicas. Não obstante, os caminhos da semiformação conduzem muitas vezes a barbárie, que por vezes é encontrada dentro dos próprios espaços educativos, oriundos da ausência de formação adequada, pela precarização de recursos e investimentos, e pela própria fragilidade que o sistema educativo se encontra, pelo autoritarismo e dominação. Adorno (2003) esclarece que para rompermos o ciclo de barbárie primitiva é imprescindível educar contra a barbárie desde a primeira infância. Saito e Oliveira (2018, p. 10) esclarecem que é urgente:

Educarmos nossas ações para uma atuação comprometida com o desenvolvimento integral da criança, de modo a mediar situações voltadas aos conceitos humanizadores do ensino, que são: criticidade, criatividade, expressividade, reflexão etc. Nesse prisma, os saberes e os fazeres docentes na educação para a infância não podem ser cristalizados por práticas pedagógicas amorfas e submissas frente à reprodução servil do conhecimento.

Todavia, muitos professores optam por uma formação aligeirada e tecnicista, a fim de ingressar o quanto antes no mercado de trabalho. "A ilusão da vida moderna conduz profissionais educacionais para o desenvolvimento de personalidade extraordinariamente superficial, com ações conduzidas pela repetição, acriticidade e o conformismo pedagógico" (SAITO; OLIVEIRA, 2018, p. 7).

Esse aligeiramento contribui para fragilidade do sistema educativo, corroborando para um efeito dominó, que culmina num tipo de "mesmice pedagógica". Deste modo, os professores “[...] limitam-se a desenvolver e repassar conteúdos de forma autoritária, conhecimentos préestabelecidos e cristalizados. E o que é para ser uma educação para formação cultural adequada, transforma-se em semiformação. A educação torna-se, assim, vazia e sem sentido.” (SILVA, 2019, p. 117).

Adorno (2003) esclarece que ninguém está livre dos traços de barbárie e que tudo dependerá de orientar esses traços. Diante disso, entendemos que para obtermos uma sociedade desbarbarizada, é preciso rever as práticas educativas, a fim de que sejam em prol de uma autorreflexão crítica. 
No que concerne ao âmbito escolar, compreendemos e partilhamos da crença que o papel da escola e da educação deve ser na contramão dos ideais capitalista, buscando pelas relações sociais a transmissão do conhecimento, a valorização do pensamento crítico, reflexivo, proporcionando experiências enriquecedoras que contribua para a formação humana. "A necessidade é que a educação seja mais do que o simples 'ajuste das pessoas' a um determinado sistema social, mas o de compeli-las para propostas que atendam às exigências para formação de 'espíritos livres'.' (SILVA, 2019, p. 118).

Entendemos que a educação é muito além do que ajustes de pessoas, é através dela que podemos orientar a sociedade contra as formas de massificação, alienação e submissão. Para tanto, é preciso que os professores corroborem para uma educação reflexiva, suscitando o pleno desenvolvimento da aprendizagem, criticidade, autonomia, potencializando as relações humanas. Por isso, partilhamos da importância de uma formação inicial e continuada de modo ressignificado, que seja capaz de formar indivíduos resistentes e emancipados, capazes de resistir a todo sistema opressor.

\section{CONSIDERAÇÕES FINAIS}

Vislumbramos neste trabalho como os aspectos sociais, econômicos e culturais interferem de forma significativa na formação dos professores da infância e consequentemente na educação das crianças pequenas visto que a educação está subordinada às demandas do capital.

Retomando ao objetivo principal deste trabalho de refletir sobre a formação de professores para a infância, com o intuito de encontrar resquícios de uma educação potencializadora e comprometida com a desbarbárie social, evidenciamos que a formação de professores tem sido orientada por uma razão instrumentaliza envolta pela cultura administrada na Indústria Cultural que acaba limitando a formação humana das crianças adaptando-as e conformando-as.

É importante ressaltarmos que, dentre as lacunas na formação, podemos ressaltar àquelas que temos vivenciado nos últimos anos, as quais estão pautadas em uma formação aligeirada e mecânica, na desvalorização da própria profissão e pela formação empobrecida que esses profissionais recebem durante a vida. As críticas feitas por muitos autores e historiadores a respeito das dificuldades de acesso às cadeiras universitárias ao longo da história foram ocupadas pelos discentes e por uma formação propriamente técnica, com uma superficialidade de conteúdos e avaliações, numa perspectiva reducionista.

Uma formação que atenda as demandas do capital impede uma formação substanciada pela práxis, categoria essencial na formação inicial e continuada de professores, que ocorre através do 
diálogo e de reflexões entre discente/discente e discente/docente e acabam prejudicadas por uma formação empobrecida. É importante destacarmos que, embora haja muitas críticas às modalidades existentes, as lacunas na formação docente não podem somente ser atribuídas a um único modelo concomitante ao uso das tecnologias, mas a formação oferecida em qualquer curso de formação de professores e que tem como prioridade a formação imediatista para o mercado de trabalho, resultando de forma direta na (des) potencialização formativa e lúdica das crianças.

A formação preconizada pela Teoria Crítica da Sociedade busca romper com os processos deformativos culturais, culminando em uma educação emancipatória que se inicia desde a mais tenra idade. Formar professores críticos resultaria, portanto, em uma educação para a infância humanizadora, em suas relações de afeto, sensibilidade ou outro, com um pensamento coletivo que vislumbre uma mudança social frente à sociedade administrada, instrumentalizada e de contradições.

\section{REFERÊNCIAS}

ADORNO, Theodor W. Educação e emancipação. São Paulo: Paz e Terra, 2003.

ARENDT, Hannah. Entre o Passado e o Futuro. São Paulo: Perspectiva, 2016.

BANDEIRA, Belkis Souza; OLIVEIRA, Avelino da Rosa. Formação cultural e semiformação: contribuições de Theodor Adorno para pensar a educação hoje. Educação, Porto Alegre, v. 35, n. 2, p. 225-232, maio/ago. 2012.

BENJAMIN, Walter. Experiência e pobreza. In: Obras Escolhidas 1. Magia e Técnica. Arte e Política. São Paulo: Brasiliense, 1985. Disponível em:

$<$ https://bibliotecasocialvirtual.files.wordpress.com/2010/06/walter-benjamin-experiencia-epobreza.pdf>. Acesso em: 30 mar. 2021.

HUIZINGA, Johan. Homo ludens.4 ed. São Paulo: Perspectiva, 2000. Disponível em: <http://jnsilva.ludicum.org/Huizinga_HomoLudens.pdf>. Acesso em: 28 mar. 2021.

LAFER, Celso. Hannah Arendt: pensamento, persuasão e poder. 3. ed. Rio de Janeiro: Paz e Terra, 2018.

OLIVEIRA, Marta Regina Furlan de; BUENO, Sinésio Ferraz. Educação e trabalho docente à luz dos conceitos de semiformação e indústria cultural: implicações na contemporaneidade.

Comunicações, Piracicaba, v. 23, n. 1, p. 239-248, jan./abr. 2016.

SAITO, Heloísa Toshie Irie; DE OLIVEIRA, Marta Regina Furlan. Trabalho docente na educação infantil: olhares reflexivos para a ação intencional e planejada do ensino. Imagens da Educação, v. 8, n. 1, p. e 39310-39310, 2018. 
SILVA, Alex Sander da. Educação e experiência estética: desencantamento do conceito educativo. Santa Catarina: EdiUnesc, 2019.

SILVA, Anilde Tombolato Tavares da. BUENO, Sinésio Ferraz. Indústria cultural e mercantilização da cultura como projeto de semiformação na educação moderna. Perspectiva (UFSC), v. 35, p. 1164, 2017.

SILVA, Vandel Pinto da. Formação de professores na perspectiva da filosofia da práxis: quem educa o educador?. In: MILLER, Stela; BARBOSA, Maria Valéria; MENDONÇA, Sueli Guadelupe de Lima (Org.). Educação e Humanização: as perspectivas da teoria históricocultural. Jundiaí: Paco Editorial, 2014. p. 83-96.

OLIVEIRA, Marta Regina Furlan de. A lógica do consumo na sociedade contemporânea e sua influência no processo de formação do pensamento infantil. 2011.Tese (Doutorado em Educação). Universidade Estadual de Maringá. Maringá, 2011. Disponível em:

<http://www.ppe.uem.br/SITE\%20PPE\%202010/teses/2011\%20->. Acesso em: 26 mar. 2021.

OLIVEIRA, Marta Regina Furlan de; AGOSTINI, Nilo. Sociedade Multitela e a

Semiformação: um desafio ético de grande monta. Revista Eletrônica de Educação, v. 14, p. 1-13, e 3753069, jan./dez. 2020.

ZUIN, Antônio A. S; PUCCI, Bruno; OLIVEIRA, Newton Ramos de. Adorno: o poder educativo do pensamento crítico. $3^{\text {a }}$ Ed. Petrópolis: Editora Vozes, 2001. 